\title{
NUEVA CIUDADANÍA PARA EL TERCER MILENIO*
}

\author{
Gloria Pérez Serrano \\ Universidad de Sevilla
}

\begin{abstract}
RESUMEN. El concepto de ciudadanía en las sociedades multiculturales esta experimentado cambios profundos. La nueva ciudadanía que emerge en el alborear del tercer milenio presenta exigencias y posibilidades diversas; los ciudadanos deben estar preparados para afrontarlos.

Se abordan en este trabajo los horizontes de la nueva ciudadanía, los nexos entre ciudadanía y nacionalidad, la formación del buen ciudadano crítico así como las dimensiones de esta ciudadanía: democrática, social, paritaria, intercultural y ambiental. Se pone de relieve que el ciudadano en la sociedad actual debe construir su identidad con pertenencias múltiples y aprender a convivir en la diversidad.

ABSTRACT. The concept of citizenship in multicultural societies is undergoing a series of deep changes. This new citizenship which is emerging in the dawn of the Third Millenium presents different requirements and possibilities and citizens must be ready to face them.

In this work, we consider the horizons of the new citizenship, the links between citizenship and nationality, the development of proper critical citizens, as well as the dimensions of this citizenship, namely democratic, social, equal, intercultural and environmental. The fact that citizens in current societies must be able to build their identity on the basis of multiple memberships and learn to coexist in diversity is also highlighted.
\end{abstract}

La nueva ciudadanía que emerge en el alborear del tercer milenio presenta exigencias y posibilidades diversas. La sociedad está experimentado cambios substanciales y los ciudadanos deben estar preparados para afrontarlos.

Se abordan en este trabajo los horizontes de la nueva ciudadanía, los nexos entre ciudadanía y nacionalidad, la formación del buen ciudadano crítico así como las dimensiones de esta ciudadanía: democrática, social, paritaria, intercultural y ambiental. Se pone de relieve que el ciudadano en la sociedad actual debe construir su identidad con pertenencias múltiples y aprender a convivir en la diversidad.

Se habla de sociedades postmodernas, sociedades de la información y del conocimiento, cibernéticas y globalmente economizadas. Las sociedades son cada vez mas pluriculturales y multiétnicas (Ruiz de Olabuénaga, 2000, 7) indica: "sería apropiado hablar de sociedades migratorias en las que las salidas del hogar y de las patrias nativas es un precio casi universal que hay que pagar para poder sobrevivir y progresar en ellas. Son sociedades sometidas a procesos millonarios de emigraciones e inmigraciones, que las han cambiado de sociedades autocontenidas en sociedades migracionalizadas".

* Un breve resumen del presente artículo ha sido publicado en el Libro de Comunicaciones del XII Congreso Nacional y I Iberoamericano de Pedagogía. 
Ante esta situación el autor se pregunta ¿puede nuestro concepto de democracia tolerar que se construya un muro de miles de millones de pesetas para obligar a estos ciudadanos a seguir padeciendo esta tortura colectiva?

La política de la Comunidad Europea ¿concuerda con los criterios de la democracia y de los derechos universales del ser humano o mantiene una cobertura al racismo, a la xenofobia y a la dictadura internacional de la riqueza frente a la indigencia?

Existe aunque de forma solapada lo que (Herman Tertsch, 1992) define como el miedo al otro: Europa se debate en miedo y pánico ante la amenaza de inmigración exterior, un fenómeno tan antiguo como el mundo y que todas las generaciones creen sufrir como nunca. Los ricos de esta tierra se sienten acosados por el miedo a tener que compartir, al menos parte de los sinsabores que la existencia depara a los miserables de otros continentes y regiones. $Y$ este miedo hace tomar medidas para protegernos a la infiltración extranjera.

Los movimientos migratorios han existido siempre si bien se han acentuado hacia Europa en las últimas décadas, por lo que aparece con una faz cada vez mas variopinta de rostros y colorido conformando su geografía.

El multiculturalismo ha surgido como situación social que afecta cada vez a mas comunidades y escuelas. Las cuales se han convertido en microcosmos de la diversidad cultural de la sociedad mundial. La convivencia entre personas de culturas diferentes se convierte en una condición primordial para un clima sano de aprendizaje. Estas nuevas circunstancias han creado, a veces, problemas de difícil solución. Sin embargo, este desafío constituye una oportunidad para educar en un clima multicultural, desde la perspectiva de un pluralismo positivo, orientado a una cultura de la paz.

La educación para la ciudadanía en un mundo planetario se enfrenta con nuevos retos y dimensiones. El concepto de Estado-Nación ha entrado en crisis y el ciudadano debe construir su identidad desde pertenencias múltiples, viviendo la diversidad como horizonte de su existencia.

Los países como España que han pasado de ser países de emigración a inmigración deben plantearse cuestiones importantes como: ¿qué valores serían necesarios cultivar para salvaguardar la democracia y la paz social e intentar no caer en el racismo y la xenofobia?

En el programa de la UNESCO aprender para el siglo XXI, coordinado por (Delors, 1996), señala cuatro pilares de la educación del futuro: aprender a conocer, aprender a actuar, aprender a vivir juntos, y aprender a ser. En esta ocasión prestaremos una atención especial a la dimensión que hace referencia a aprender a vivir juntos, a convivir.

Este objetivo de enseñar a convivir en sociedades democráticas, a dialogar, a estar con el otro, a valorarlo y a disfrutar de su compañía, exige aprendizaje, ejercicio y práctica. No podemos olvidar que no hay democracia duradera sin demócratas, es decir, sin ciudadanos deseosos y capaces de jugar un papel, activo y responsable en la sociedad.

\section{Educación para la ciudadanía. Objetivo y finalidad}

El ser humano no nace ciudadano; tiene que hacerse en el tiempo y en el espacio. Ser ciudadano implica formar parte de la "Civis", con una serie de derechos y de deberes. 
La ciudad constituye el espacio vital cotidiano para la mayoría de los ciudadanos. Nos pasa muchas veces desapercibida, pero tiene un interés decisivo en nuestra vida. La ciudad, decía Plutarco, que "es el mejor educador". Se hace, pues, imprescindible el estudio y la reflexión sobre la función que desempeña, los problemas que presenta y las soluciones que puede ofrecer.

Los ciudadanos romanos estaban obligados a conocer cuáles eran sus derechos y sus deberes para ejercer los unos y cumplir los otros. A este conocimiento se llamaba civismo, entendido como el arte de vivir en la ciudad o bien el modo de vida propio del ciudadano. El civismo entraña el buen uso de nuestra convivencia.

La importancia del civismo era grande. De acuerdo con el conocimiento de sus derechos y de sus obligaciones, los ciudadanos no descuidaban su participación ni su responsabilidad en el desarrollo de la sociedad política que más tarde se llamó Estado. El civismo facilitó el constante progreso de aquellas ciudades. Lo cívico remite a la ciudad y a los ciudadanos. También a lo patriótico. En la actualidad la palabra civismo, en sentido literal, se aplica al modo de vivir en la ciudad y a la que es propio del ciudadano. Hace referencia al arte de convivir.

La base ética de la convivencia se encuentra en la llamada regla de oro con una aplicación muy general: "No hagas a los demás lo que no quieres que te hagan a ti".

La Educación Cívica tiene como objetivo ayudar a las personas a convivir en los grupos humanos. Se ha dado mucha importancia a lo que hemos denominado educación para la convivencia democrática. Significa, por un lado, actuar de modo que beneficie y potencie las relaciones humanas y sociales, ateniéndose a las normas establecidas, participando en actividades colectivas e intentado cooperar con los otros para resolver problemas comunes. Por el otro, no hacer nada que perjudique la convivencia (incumplir leyes, alterar el orden o atentar contra personas o cosas) que vaya en contra de la convivencia democrática. Desde esta óptica, la democracia se define no sólo por ser un tipo de gobierno sino, sobre todo, un estilo de vida, un planteamiento ante los demás caracterizado por establecer una defensa de la persona frente a la sociedad. Queda superada así la clásica definición de democracia como "gobierno del pueblo para el pueblo" y también superados los límites de lo meramente institucional.

La idea fuerza de la educación para la ciudadanía tiene como referencia fundamental: la universalidad de la dignidad humana. La ciudadanía trata de hacer emerger un nuevo modelo de desarrollo en el mundo, digno de todo ser humano.

Para entender el valor de la persona humana recordemos el Art. 1 de la Declaración Universal de los Derechos Humanos, que dice: "Todos los seres humanos nacen libres e iguales en dignidad y derechos y, dotados como están de razón y consciencia, deben comportarse fraternalmente los unos con los otros".

Esta valoración de la persona nos lleva a fomentar una mayor igualdad social. Los pobres, no lo son sólo en sentido estrictamente económico, sino también en el más amplio de pobreza, como carencia de oportunidades. Es necesario fomentar el desarrollo humano, entendido como "el proceso que permite a las personas ampliar la propia escala de opciones". El rédito es una de estas opciones, pero no representa la suma total de las experiencias humanas. La salud, la instrucción, el ambiente sano y la liber- 
tad de acción y de expresión son factores igualmente importantes. El desarrollo humano, no puede promoverse desde la dirección única del crecimiento económico.

Existe una gran coincidencia entre los autores más diversos en considerar que el objeto de la Educación Cívica es la formación del buen ciudadano, aunque discrepen en lo que se entiende por buen ciudadano.

La defensa de los derechos humanos puede convertirse en un elemento unificador que aúne los esfuerzos actuales para producir ciudadanos informados y activos, tanto en el ámbito de sus comunidades como de sus países y de un mundo interdependiente.

Desde esta perspectiva se ha firmado la carta europea de salvaguarda de los Derechos Humanos en la ciudad (Saint-Demis, Mayo, 2000) en la que puede leerse:

La ciudad es hoy el espacio de todos los encuentros y, por lo tanto, de todas las posibilidades. Asimismo es el terreno de todas las contradicciones y de todos los peligros: en el espacio urbano de fronteras inciertas aparecen todas las discriminaciones ancladas en el paro, la pobreza, el desprecio de las diferencias culturales, mientras que, al mismo tiempo, se esbozan y se multiplican prácticas cívicas y sociales de solidaridad.

Aquí es donde se abren las condiciones para una democracia de proximidad. Se presenta una ocasión para que todos los ciudadanos y ciudadanas participen en la ciudadanía: una ciudadanía de la ciudad. Si cada derecho definido pertenece a cada uno, cada ciudadano, libre y solidario, debe garantizarlo también a los demás.

\section{Horizontes de la nueva ciudadanía}

El concepto de ciudadanía se entiende, en primer lugar, como status jurídico que uno adquiere por vivir en un determinado espacio político. Status que le confiere, lógicamente, una serie de derechos y libertades, a la vez que deberes. En segundo lugar, podemos entender también que este concepto recoge la decisión clara de erigir un futuro común y de tomar parte en su construcción. Sin una posibilidad de participación, no podríamos hablar plenamente de ciudadanía.

Para favorecer la práctica de la ciudadanía se tienen que propiciar determinadas condiciones. Los ciudadanos deben tener posibilidades reales de actuación y éstas requieren unas condiciones socioeconómicas mínimas, fomentar la participación, propiciar la descentralización de las funciones y de los roles de las tareas políticas.

El debate se cifra hoy en torno a las condiciones de ciudadanía, la atribución de poderes y la creación de oportunidades para los ciudadanos.

Es necesario educar a los individuos para que conozcan sus derechos y deberes y se comprometan a cumplirlos. No deben existir ciudadanos que se sitúen fuera de las reglas consensuadas. Las comunidades tienen el deber de comprometerse a forjar los roles que conlleven el buen ejercicio de la ciudadanía. El carácter individual de los ciudadanos se forja en la práctica de la ciudadanía abierta a las exigencias comunes. Hoy se pone el acento en la dinámica de la participación de los individuos, partiendo de la base de que "a participar se aprende participando". La ciudadanía como afirma (Camps,1998,80): "hay que entenderla como una cierta dedicación y cooperación con lo público, lo que es de todos". 
El concepto de ciudadanía en Occidente presenta nuevas tensiones e interrogantes a los que habrá que buscar respuestas. Entre ellas podemos destacar:

\section{El nexo entre ciudadanía y nacionalidad}

El nexo entre ciudadanía local y mundial. Como señala el informe (Delors, 1996, 55): "La participación en la propia comunidad es un prerrequisito necesario para ser un miembro activo de la comunidad internacional porque ¿cómo aprender juntos en la aldea planetaria si no podemos vivir en las comunidades a las que pertenecemos: La nación, la región, el pueblo, la vecindad?". Convertirse poco a poco en ciudadanos del mundo implica participar activamente en la vida de la nación y de la comunidad local.

El nexo entre derechos individuales y derechos comunitarios y, por ello, entre el estatuto de ciudadano y el estatuto de miembro de una comunidad.

El nexo entre la igualdad entendida como homogeneización y la igualdad entendida como potencialidad.

La problemática en torno a la equidad y a la justicia se evita con fuerza en el dilema que afecta a nuestras democracias, en cuanto al equilibrio y el interés público y/o de bien común, conjuntamente a las condiciones que pueden garantizar a los ciudadanos la consecución del propio bien, armonizando una responsabilidad individual y comunitaria a la vez.

Es necesario replantearse el concepto de ciudadanía desde una perspectiva de responsabilidad ética, intentando contemplar los nuevos nudos problemáticos que presentan las sociedades multiculturales. El papel del Estado consiste en promover y garantizar el bien de la comunidad, así como el equilibrio entre los derechos individuales y las responsabilidades sociales. El bien es la clave de la política, de la moral y del derecho. Debemos tener conciencia de que es necesario partir del enfoque de la responsabilidad. Los derechos fundamentales implican obligaciones de reciprocidad y, por tanto, de responsabilidad hacia los demás. Se inscriben en un horizonte solidario, cuya aspiración puede cifrarse en: "crear el mayor bienestar para el mayor número".

\section{La formación del buen ciudadano crítico}

Al hacer alusión al buen ciudadano diversos autores ponen de relieve la existencia de, al menos, dos categorías: el ciudadano despolitizado y el comprometido. Este último se caracteriza por su implicación activa en la resolución de problemas y por dar primacía a los intereses comunes por encima de los suyos propios. Una persona socialmente activa es crítica en la forma de orientar sus relaciones sociales. Es crítico también con las reglas que rigen la conducta cívica local. Debe reconocer las leyes que le vinculan con su propio estado y normativas que lo superen como pueden ser los Derechos Humanos.

Los estudiosos de las democracias parlamentarias occidentales, ponen de relieve que se está perdiendo el necesario sentimiento de pertenencia común y el deber de compartir ciertos valores. 
Por lo que a España se refiere, en una investigación* realizada en el alborear del nuevo milenio, con jóvenes de 18-20 años, sobre ¿qué significa para ti ser un buen ciudadano?, se detectaron las siguientes categorías:

El "buen ciudadano activo", identificado por aquella persona que vota en las elecciones, pertenece a un partido político, o a un sindicato, conoce la distribución del dinero, trata de cambiar las cosas, anima a otras personas a votar... En suma, tiene un protagonismo activo en toda la vida política.

El "buen ciudadano leal y cortés", identificado con características de tipo privado (leal a la familia, educado, cortés y respetuoso). Es decir, el no político,

Finalmente el "buen ciudadano no comprometido", se refiere al que cumple los deberes cívicos sin adquirir un compromiso político (obedece la ley, paga impuestos, está informado).

Se ha considerado de gran interés extraer los valores porcentuales de los ítems del cuestionario que superan el 50\%. Así las características más elegidas son:

1. Obedece la ley

2. Paga los impuestos regularmente

3. Vota en todas las elecciones

4. Es leal a su familia

5. Es siempre educado

6. Anima a otras personas a votar

7. Trabaja mucho

8. Se ocupa de lo que pasa en el mundo
$84.8 \%$

$74.1 \%$

$74.1 \%$

$73.7 \%$

$70.2 \%$

$61.9 \%$

$58.1 \%$

$56.5 \%$

Alcanzan valoraciones muy bajas entre los jóvenes españoles la pertenencia a un partido político y a un sindicato.

El tipo de ciudadano que alcanza puntuaciones más elevadas es el no comprometido, que cumple sus deberes cívicos sin adquirir compromisos de tipo político. Esta misma tendencia se puede apreciar en diversos países europeos.

La formación del buen ciudadano implica, no obstante, desarrollar el sentido cívico y comportarse como crítico con lo que no se considere justo. La capacidad de compromiso así como el sentido crítico de transformación y mejora de las personas, es la principal motivación que nos lleva a la acción. Un ciudadano comprometido con una idea es capaz de los mayores esfuerzos, aunque esto se hace imposible cuando el ciudadano se deja arrastrar por los sentimientos de aislamiento e impotencia que genera una sociedad humanamente compleja, burocratizada, y sometida a cambios constantes e imprevisibles cuya naturaleza es difícil, por no decir imposible, delimitar.

La sociedad actual es cambiante en la sucesión de sus rasgos pero es la sociedad con la que contamos y en la que vivimos. No nos exime de aspirar a formar ciudadanos comprometidos con los problemas colectivos, dispuestos a reconstruir sus relaciones socia-

* PÉREZ SERRANO, G. (1999). Actitudes sociopolíticas de los universitarios españoles. Sevilla: Universidad. 
les con otros seres humanos, conforme a normas susceptibles de transformar las condiciones que producen, para muchas personas, una vida poco digna.

Desde el punto de vista educativo debemos aspirar a formar un ciudadano crítico y comprometido que se preocupe por denunciar los problemas y colaborar, en la medida de sus posibilidades, a la solución de los mismos.

Se trataría de conectar la formación del buen ciudadano crítico con la vida cotidiana y ayudarle a leer y comentar los hechos más significativos de la sociedad en la que vive. La adecuada elección y el cumplimiento de las metas y valores vitales están relacionados con el uso del pensamiento crítico al hacer las elecciones de vida, tanto individual como colectiva, relacionadas en sí misma con la institucionalización del ideal democrático. Es necesario formar ciudadanos democráticos como medio para mejorar la calidad de vida en los niveles individual, interpersonal e institucional. El fomento de la institucionalización del ideal democrático no se considera una meta educativa opcional en las sociedades modernas, es decir, no es un lujo que puede o no ser aceptado. El fomento del desarrollo y el uso de las capacidades críticas son elementos esenciales en la educación para la democracia.

Apostamos por lo que se ha denominado ciudadanía de máxima densidad, (Jordán, $1995,10)$, de aspiraciones elevadas. Es decir, un ciudadano que se identifique como miembro vivo de la comunidad, con una consciencia nítida respecto de sus deberes, pero también de sus responsabilidades en relación con el bien comunitario.

La Educación Cívica en sentido amplio, como educación convivencial, social y política deben buscar, sobre todo, un tipo de ciudadano que:

Es y se siente miembro de un Estado.

Está bien informado.

Ha aprendido a trabajar por su cuenta.

Sabe tomar decisiones oportunamente.

Desarrolla actitudes participativas.

Desea actuar para transformar la sociedad.

En resumen, la Educación Cívica constituye un elemento esencial en la formación integral del ser humano. Dará como resultado personas libres, capaces de articular relaciones humanas con los restantes miembros de la sociedad, fuera de la estructura política, de crear hábitos cívicos y desarrollar nuestra constitutiva dimensión social. Formará ciudadanos bien informados y miembros activos de la comunidad, conocedores de los derechos y deberes cívico/sociales que la ciudadanía entraña. El ejercicio de la ciudadanía, en suma, se expresa en una condición participativa en lo político, solidaria en lo social, respetuosa de los derechos humanos y los de la naturaleza.

\section{Dimensiones de la nueva ciudadanía}

La formación para el ejercicio de la participación cívico-social, para el desarrollo de los derechos y responsabilidades cívico-sociales y culturales, demanda la preparación en contenidos esenciales en este ámbito tales como: "La formación para asimilar las normas y valores que facilitan la convivencia y poder participar activamente en las actividades sociopolíticas en las diversas instituciones: familia, municipio, provincia, comunidad, estado, organismos internacionales, así como otras asociaciones que res- 
ponden a valores: deportivos, filantrópicos culturales y religiosos". (Marín Ibáñez, 1998).

Se hace cada vez más necesario propiciar en los individuos la capacidad para aprender a vivir juntos, a convivir en sociedades cada vez más plurales. Fenómenos como la globalización, la mundialización y la sociedad de la información que lo permeabilizan todo, plantean nuevos desafíos. El ciudadano está implicado en tiempo real con toda la humanidad. Nada le puede ser ajeno. Por otra parte, con palabras de Daniel Bell: "El Estado se volvió demasiado pequeño para hacer frente a los grandes problemas y demasiado grande para resolver los pequeños". Vinculamos con frecuencia la ciudadanía con un formato de identidad nacional que el Estado debería proteger. Pero en la actualidad, la ciudadanía única no va sincronizada con el reloj de la humanidad. La Ciudadanía Única tiene que enfrentarse con múltiples sistemas de pensamiento, a veces en conflicto.

La ciudadanía del siglo XXI basa su riqueza en el cultivo de la variedad y la heterogeneidad. La sociedad del futuro será cada vez más plural, un crisol de la diversidad humana. Es necesario fortalecer la cohesión social sobre la base de la aceptación consciente de la existencia del "otro", del diferente. El nuevo ciudadano en la sociedad actual puede tener pertenencias múltiples.

Recordamos algunas dimensiones esenciales de la nueva ciudadanía (Carneiro, 1999) que vienen a dibujar un cambio del paradigma.

\section{Ciudadanía democrática:}

Reconoce como central el valor inalienable del ser humano y de su dignidad. Fomenta la cultura de la paz como parte integrante de esta misma cultura cívica. Desarrolla competencias sociales para la negociación democrática de puntos de vista y de soluciones comunitarias. Recoge dentro del pluralismo el oxígeno indispensable para prosperar.

La ciudadanía democrática requiere potenciar la participación de los ciudadanos en la causa publica. En este sentido las Comunidades Europeas en el Año Internacional de la Educación Permanente, en las Conclusiones del Consejo sobre una Política de Educación Permanente dice el Diario Oficial del (20-12-1996):

"Las iniciativas de la Educación Permanente deberían lograr un equilibrio adecuado entre las dimensiones personales, culturales, cívicas y sociales y las preocupaciones económicas y laborales, e incluir además los principios democráticos y los valores relacionados en los derechos humanos... La Educación Permanente debería fomentar la participación activa en la sociedad democrática... debe adoptar un enfoque claramente integral en lo que respecta al desarrollo del individuo y la comunidad local. Por último, es importante fomentar la participación activa de todos los ciudadanos en el proceso político y democrático".

\section{Ciudadanía social:}

Hace referencia a la integración de los derechos y los deberes de la justicia social en la conciencia de cada ciudadano.

La ciudadanía moderna exige un fuerte componente social ante los fenómenos de pobreza, exclusión y marginación social, en defensa de los más débiles. Ejercer la ciu- 
dadanía desde esta óptica es vivir la solidaridad como camino y meta de acumulación de capital social. Es necesario fomentar competencias que propicien la capacidad de vivir en armonía con otros.

El concepto de Estado-Nación ha entrado en crisis. Estamos asistiendo a la tendencia a construir políticas supranacionales, capaces de enfrentar nuevos desafíos como los que se plantean tanto en el ámbito planetario como multinacional. Ahí están las transacciones financieras internacionales, los problemas derivados del cuidado del medio ambiente, la expansión internacional del delito y la expansión de internet como vehículo de circulación de información.

Como resultado de estos procesos, el concepto de ciudadanía asociado a la Nación se desdibuja. Aparecen dos fenómenos de gran interés, la adhesión a entidades supranacionales así como el repliegue hacia el comunitarismo local. La aparición de lo local y lo supranacional como nuevos espacios de participación social, está asociada a fenómenos de ruptura de la acción política, tal como se la concebía hasta ahora.

El hallazgo de un concepto de ciudadanía mundial, ciudadanía planetaria, exige otro de solidaridad vinculado a la pertenencia al género humano. No obstante, esta perspectiva se encuentra con muchas dificultades, vinculadas sobre todo a las formas a través de las cuales se está produciendo el proceso de globalización. Un hecho que rompe los compromisos y formas de solidaridad y de cohesión con nuestros semejantes que nos eran habituales. La solución a este reto por parte de los que quedan excluidos de la globalización, es el refugio en la identidad local, donde la cohesión del grupo se apoya en el rechazo a los "externos". La ruptura con los vínculos tradicionales de solidaridad está generando nuevas formas de exclusión, de soledad y de marginación.

\section{Ciudadanía paritaria:}

Liberada de toda discriminación de género que impide la realización de una verdadera ciudadanía a dos. El valor de la igualdad teóricamente proclamado, sigue sin conseguirse en la práctica. La paridad es una conquista difícil, aunque indispensable para el progreso humano, social y democrático. La liberación del prejuicio de género es parte integrante de la nueva ciudadanía.

\section{Ciudadanía intercultural:}

La ciudadanía monocultural pertenece al pasado. La sociedad actual es creciente, plural y compleja. El desafío irrenunciable de la ciudadanía moderna consiste en crear un marco necesario de cohesión en el respeto de las diferentes culturas y de los derechos colectivos que legitiman su libre expresión.

Existe un gran numero de emigrantes ilegales en todos los países que entran a formar parte de lo que se denomina ciudadanía irregular, lo que equivale a entrar en el mundo de la emergencia, de la subsistencia, de la marginación social, de la eventualidad y de la indefensión institucional. Estos procesos de opacidad social y de invisibilidad cívica es la condición que distingue el emigrante regular del irregular. Esta condición de marginalidad se traduce como señala (Ruiz de Olabuénaga, 2000) en dos ámbitos relacionados pero diferentes entre sí: a) el de las necesidades cotidianas de supervivencia social; $y$ el b) de las relaciones institucionales. 
La ciudadanía intercultural es un medio para afirmar la cultura de la tolerancia y de la paz que propicie la construcción de la identidad no contra los otros sino con los otros. No hay ninguna cultura autosuficiente; la que se cierra sobre sí misma tiende a extinguirse. Toda cultura auténtica anhela lo universal, que sólo se puede entrever en el reencuentro con otras culturas.

La ciudadanía intercultural presupone la adquisición de nuevas competencias relacionadas y comunicativas, con el fin de abrirse al diálogo y al enriquecimiento mutuo. Es necesario descubrir, bajo la capa de la diferencia, nuestra común humanidad.

\section{Nueva ciudadanía ambiental:}

La nueva ciudadanía guarda relación con la calidad de la naturaleza y su preservación. El ser humano no puede consumir egoístamente los recursos naturales. Es necesario defender una nueva ética de relación con la naturaleza. Lo que existe es para beneficio de las generaciones humanas sucesivas y no sólo para goce de las generaciones actuales.

La educación ambiental es parte necesaria de la educación cívica y moral en la conquista de una ciudadanía que tiene sus cimientos en valores de respeto a la naturaleza, cuya diversidad es necesario proteger.

Ser ciudadano en una sociedad democrática implica interiorizar valores cívicos, orientados a alumbrar un nuevo humanismo como condición de la ciudadanía. Ya en el siglo XV afirmaba, Pico della Mirandola, en su Oración sobre la dignidad del hombre: "Hay que conquistar la humanidad".

Conviene subrayar en suma, que en una sociedad pluralista como la nuestra, la búsqueda y la promoción de valores comunes contribuyen a la construcción y al desarrollo de un espacio democrático en el que el conjunto de la población tenga derechos ciudadanos.

El objetivo que se pretende con la formación ciudadana es llegar a crear una cultura de los derechos humanos, que lleve a respetar al otro, aunque no pueda obligar a aceptarlo en el sentido más amplio del término, como puede obligar la ley.

Es necesario identificarse con valores como la libertad, la cohesión social y el respeto por la diversidad de identidades y culturas; la protección del medio ambiente; la igualdad de oportunidades con relación al acceso al trabajo, al salario y al reparto de las responsabilidades familiares entre hombres y mujeres; al acceso al consumo y a la creación cultural. Construir, de este modo, una ciudadanía paritaria con el fin de generar mayor calidad de vida para todos los ciudadanos y ciudadanas.

En el siglo XXI las políticas de ciudadanía irán mas allá del Estado-Nación. Necesitarán aprender la complejidad estructural emergente y las nuevas dinámicas de la sociedad postindustrial y postnacional que influyen en la ciudadanía, atravesadas por la cuestión de género, con el fin de asegurar que las mujeres lleguen a alcanzar la igualdad de derechos y de deberes en todos los niveles y esferas.

En el futuro, el concepto de ciudadanía se debe definir desde nuevas perspectivas. El período en el que ha sido posible concebir la ciudadanía en general y la ciudadanía social en términos nacionales y de un estado del bienestar, creemos que ha tocado a su fin. Se están desarrollando nuevos ideales acerca de los derechos ciudadanos, 
tales como: "Derechos de la tierra", a " un medio ambiente sano", "derechos de los no nacidos" y "derechos culturales", la "ciudadanía global". Todos ellos se enriquecen a la vez que hacen complejo lo que tiene que ver con la ciudadanía, como aquellos elementos que incorporan las nociones de igualdad humana, identidad territorial y local, de nación y herencia.

El ciudadano en la sociedad actual debe construir su identidad con pertenencias múltiples: local, nacional, internacional, político, religioso, artístico, económico, familiar, etc. Lo propio de la ciudadanía moderna es, precisamente, la pluralidad de ámbitos de desempeño y la construcción de la identidad a partir precisamente de esta pluralidad y no de un solo eje dominante o excluyente.

Las sociedades actuales serán cada vez más complejas en cuanto a su composición variedad y riqueza. La formación del buen ciudadano en sociedades multiculturales, precisa del desarrollo del mejor sentido cívico y de una renovada práctica de la ciudadanía. El civismo para ser tal debe apuntar forzosamente a este hito amplio y universal. Desde esta óptica adquiriría sentido el civismo nacional. Es preciso estimar y respetar a las personas del mismo pueblo, del mismo entorno y nación, para después extender este amor, respeto y compromiso hacia todos los seres humanos, hasta los pueblos más lejanos y desconocidos.

En la sociedad actual, se valora cada vez mas la capacidad de diálogo, de relación, de comunicación y de convivencia. Mirando al futuro las redes telemáticas nos facilitarán la posibilidad de contactar con el otro, distante y lejano debemos cultivar, también, el vínculo convivencial y relacional con el próximo, el vecino, hermano, amigo y compañero. La convivencia se crea, se desarrolla y se cultiva, no es algo que nos venga dado, exige tiempo, cuidado, recreación y, sobre todo, presencia, estar con y sentir con el otro. Lo interesante es que en este proceso es que en la construcción de este camino cambian tanto los que lo hacen como a los que se destina. Aprender a vivir juntos,"a convivir", desarrolla las potencialidades del ser mas profundo y originario de la persona. Desde esta óptica, podemos crear y recrear una cultura genuina de la paz, la tolerancia y la democracia.

La paz es posible en la sociedad actual, en el entorno y en la familia. Se crea a través de la justicia y de la pacificación del corazón. Su construcción exige el esfuerzo de todos.

Recojo para finalizar las palabras de un monje budista por su contribución al tema que nos ocupa.

"El sufrimiento de nuestro país ha sido profundo.

De este sufrimiento surge una gran ternura.

La ternura pone paz en el corazón. Un corazón pacífico da paz al ser humano.

Un ser pacífico pone paz en una familia.
Una familia pacífica pone paz en una comunidad.

Una comunidad pacífica pone paz en una nación.

Una nación pacífica pone paz en el mundo". 


\section{Bibliografía}

CAMPS, V. y GINER, S. (1998). Manual de civismo. Barcelona, Ariel.

CARNEIRO, R. (1999). Proyecto educativo de ciudad. Educación para la ciudadanía, Congreso por el conocimiento y la convivencia. Barcelona, Abril.

COMISIÓN DE LAS COMUNIDADES EUROPEAS (1994). Libro Verde. Política Social Europea. Luxemburgo, Comunidad Europea.

COMISIÓN EUROPEA (1996). Enseñar y aprender. Hacia la sociedad del conocimiento. Libro Blanco sobre la educación y la formación. Luxemburgo, Oficina de Publicaciones Oficiales de las Comunidades Europeas.

DELORS, J. (Coord) (1996). La educación encierra un tesoro. Informe a la UNESCO de la Comisión Internacional sobre la educación para el siglo XXI. Madrid, Santillana.

JORDAN, J. A. (1995). Concepto y objeto de la Educación Cívica. Revista Pedagogía Social. 10, pp. 7-18.

MARÍN IBAÑEZ, R. (1998). La Educación Permanente: posibilidades a nivel nacional e internacional. En Jornadas de Educación Permanente. Gijón, C. A. UNED, pp. 19-52 PEREZ SERRANO, G. (1999). Aprender a convivir. Buenos Aires, Docencia.

RUIZ DE LA OLABUENAGA, J. I. (2000). Inmigrantes. Madrid, Acento. 